\title{
Interfacing the NRL 1-D High Vertical Resolution Aerosol Model with COAMPS
}

\author{
William Hoppel \\ Computational Physics Inc. \\ 8001 Braddock Road \\ Springfield VA 22151 \\ phone: (202)767-2951 fax:(202)404-8011 email:wmhoppel@ccf.nrl.navy.mil \\ Peter Caffrey \\ Code 7228 \\ Naval Research Laboratory \\ Washington DC 20375 \\ phone: (202)767-3589 fax:(202)404-8011 email: peter.caffrey@nrl.navy.mil
}

Award Number: N0001406WX20574

\section{LONG TERM GOALS}

Identify, understand and quantify all the physical processes that govern the aerosols in the marine environment and develop a mechanistic model that predicts the evolution of the aerosol size and composition distribution. From such a model, aerosol extinction of EM radiation can be calculated in a highly structured atmospheric marine boundary layer (AMBL) and used to evaluate and predict the performance of systems that operate at visible and infrared wavelengths.

\section{OBJECTIVES}

The objectives of the current work are:

(1) To develop an interface which allows the NRL aerosol model (MARBLES, Fitzgerald et al. 1998) to assimilate the required meteorological data from the output of a meteorology model. This provides data necessary to calculate an air mass trajectory along which the aerosol model can travel to any geographical point in the domain, and will supply the many meteorological inputs required by the aerosol model (MARBLES).

(2) Add to the aerosol model the capability to include large-scale vertical air motions (subsidence/lifting) given by the meteorological model. This is a major task because each size section moves with a different vertical velocity given by the sum of the gravitational settling velocity and the vertical air velocity, and because changes in vertical air velocity require horizontal divergence that also changes the aerosol concentration in a vertical cell. In prior versions of the aerosol model the only vertical exchanges were those resulting from gravitational settling and turbulent mixing.

(3) Develop new parameterization for sea-salt aerosol for use in numerical models. Deposition of particles at the surface must also be parameterized in numerical models. Surface deposition algorithms, in existing models, are for particles that originate from above or upwind of the point of deposition. We have determined that deposition of particles from a uniform surface source, such as sea-salt aerosol, is fundamentally different than for deposition of particles from above. 


\section{Report Documentation Page}

Form Approved

OMB No. 0704-0188

Public reporting burden for the collection of information is estimated to average 1 hour per response, including the time for reviewing instructions, searching existing data sources, gathering and maintaining the data needed, and completing and reviewing the collection of information. Send comments regarding this burden estimate or any other aspect of this collection of information,

including suggestions for reducing this burden, to Washington Headquarters Services, Directorate for Information Operations and Reports, 1215 Jefferson Davis Highway, Suite 1204, Arlington

VA 22202-4302. Respondents should be aware that notwithstanding any other provision of law, no person shall be subject to a penalty for failing to comply with a collection of information if it

does not display a currently valid OMB control number.

1. REPORT DATE

30 SEP 2006

4. TITLE AND SUBTITLE

Interfacing the NRL 1-D High Vertical Resolution Aerosol Model with COAMPS

6. AUTHOR(S)

7. PERFORMING ORGANIZATION NAME(S) AND ADDRESS(ES)

Computational Physics Inc,8001 Braddock Road,Springfield,VA,22151

9. SPONSORING/MONITORING AGENCY NAME(S) AND ADDRESS(ES)

12. DISTRIBUTION/AVAILABILITY STATEMENT

Approved for public release; distribution unlimited

13. SUPPLEMENTARY NOTES

14. ABSTRACT

15. SUBJECT TERMS

16. SECURITY CLASSIFICATION OF:

a. REPORT

unclassified b. ABSTRACT

unclassified c. THIS PAGE

unclassified
17. LIMITATION OF ABSTRACT

Same as Report (SAR)
3. DATES COVERED

00-00-2006 to 00-00-2006

5a. CONTRACT NUMBER

5b. GRANT NUMBER

5c. PROGRAM ELEMENT NUMBER

5d. PROJECT NUMBER

5e. TASK NUMBER

5f. WORK UNIT NUMBER

8. PERFORMING ORGANIZATION REPORT NUMBER

10. SPONSOR/MONITOR'S ACRONYM(S)

11. SPONSOR/MONITOR'S REPORT NUMBER(S) 
(4) Use the data generated by the integration of COAMPS and MARBLES during the period of the RED experiment (ONR's rough evaporation duct experiment) as a diagnostic tool to predict the aerosol size, composition, and vertical variation along the COAMPS predicted air mass trajectory, to compare the experimental results with actual measurements, and to study the sensitivity of the aerosol predictions to meteorological conditions and various aerosol parameterizations in the model.

\section{APPROACH}

To calculate/predict EM extinction (at any wavelength) resulting from aerosols in a highly structured AMBL, the evolution of the aerosol size and composition distributions are required. Many of the aerosol source, sink and transformation processes are highly dependent on meteorological parameters such as wind speed, humidity profile, clouds, precipitation scavenging, etc. The NRL 1-D aerosolprocesses model includes all these processes but needs real meteorological data as input to calculate the evolution of the size distribution. The aerosol model is typically run with 37 size sections (between 0.005 and $15 \mu \mathrm{m}$ dry radius) and four components, sulfate, sea salt, an insoluble component (dust), and water in equilibrium with the soluble components at ambient RH. To fully integrate an aerosol model into a 3-D meteorological model would require carrying and calculating over 100 aerosol variables at each grid point of the model in addition to the meteorological variables. Rather than fully integrating the aerosol model into the meteorological model the following strategy is being pursued: A highresolution mesoscale model, in our case the Navy's COAMPS model, is run over the geographical region and time of interest and the meteorological variables at each grid point are stored at specified time intervals, typically every hour. An important feature of COAMPS is the nested grid feature. After running COAMPS over a large area the output is used to initialize a nested grid, giving higher resolution to the area of interest. Also having the aerosol model independent of the meteorological model makes it possible to run the aerosol model at higher vertical resolution than is possible with COAMPS, whose vertical resolution is fixed regardless of the horizontal grid resolution. In addition to the normal meteorological fields, some internally generated parameters such as the turbulent mixing coefficients generated by the boundary layer parameterization used in the model are also saved. From the horizontal wind field, a mean AMBL back trajectory from any point of interest is generated. The NRL 1-D aerosol model, here considered as a vertical column, is advected along this trajectory. The meteorological data required by the aerosol model is extrapolated using the grid points that lie closest to the points on the back-trajectory. The height of the AMBL is determined in the model by the profile of exchange coefficients, which extends into the free troposphere.

\section{WORK COMPLETED}

The work on this phase of the long-term goals is essentially completed (i.e. the objectives stated above have been accomplished) and a comprehensive paper on the results has been submitted (February of 2006) and accepted for publication (July 2006) in the Journal of Geophysical Research (see list of publications).

\section{RESULTS}

While results of model simulations over many air mass trajectories occurring during the period of the RED experiment were generated, two open ocean trajectories that were typical of the two dominant meteorological conditions were analyzed in great detail. The four panels of Figure 1 show a sampling of the results from one of these periods. The uppermost panel shows the relevant meteorological 
dynamics occurring along the air mass trajectory where the black contours are the turbulent mixing coefficients responsible for mixing the aerosol throughout the MBL. The region of high mixing defines the AMBL. The orange areas are regions of large-scale subsidence and the blue regions of large-scale lifting. The white line is the $10 \mathrm{~m}$ wind speed that is required input for a number of the aerosol parameterizations, most notably the white cap frequency and hence sea-salt aerosol generation. The white x's indicate the presence of clouds. The second panel shows the total concentration of wet particles (in water equilibrium at ambient $\mathrm{RH}$ ) with radius greater than $0.1 \mu \mathrm{m}$. Particles larger than $0.1 \mu \mathrm{m}$ are chosen because they influence light scattering and are here predominantly sea-salt particles. The third panel gives the predicted extinction for a wavelength of $0.55 \mu \mathrm{m}$. The bottom panel shows the sulfate speciation: i.e. the amount of sulfate derived from (1) cloud processing of aerosol in the AMBL, (2) entrained from the free troposphere, (3) converted heterogeneously on sea-salt aerosol, and (4) condensed directly from the gas-phase.

The modeled aerosol concentrations over these two cases have shown that:

- Interstitial particle number and cloud condensation nuclei $(\mathrm{CCN})$ concentrations are controlled largely by a balance between (1) entrainment of FT aerosol into the MBL and (2) generation of sea-salt at the surface (which is variable with wind speed). Newly introduced aerosol mixes uniformly within the MBL within a few hours, and the contribution of small particle FT aerosol remains at approximately $2 / 3$ the FT value. Small particle sea salt aerosol concentrations are much more variable, dependent on wind speed.

- $\operatorname{CCN}\left(\mathrm{r}_{\mathrm{dry}}>0.033 \mu \mathrm{m}\right)$ concentrations were predicted to be stable near $200 \mathrm{~cm}^{-3}$ after an initialization period of approximately 24 hours, with sea-salt particles contributing $10-30 \%$ to the total during periods of typical moderate wind speed $\left(5-10 \mathrm{~m} \mathrm{~s}^{-1}\right)$. This result is largely determined by the imposed boundary condition and is somewhat larger than indicated by prior measurements in the tropics.

- Aerosol transport by large scale vertical motions (vertical velocities), while negligible over short time scales, was important in diluting the MBL with FT air over times on the order of 1 day and greater, and in predicting entrainment of FT aerosol into the MBL. Sea-salt particle concentrations were diluted by approximately $50 \%$ as compared to model runs made without transport by large-scale vertical velocities (i.e., over those runs using only a FT exchange velocity).

- Sulfate mass, under moderate winds of $5-10 \mathrm{~m} \mathrm{~s}^{-1}$, was split between influx from the free troposphere and that generated by cloud processing, with heterogeneous sulfate contributing another $\sim 10 \%$ to the total sulfate mass. However, under high winds, $\left(10-20 \mathrm{~m} \mathrm{~s}^{-1}\right)$, the larger sea-salt flux resulted in greatly enhanced heterogeneous oxidation, preferentially depleting available $\mathrm{SO}_{2}(\mathrm{~g})$ and reducing the cloud processed sulfate mass by $80 \%$ of its value run with moderate winds. Sulfate aerosol mass from condensation of gas-phase oxidation products was negligible compared to these other processes at all sizes.

- Under moderate wind speeds and greater, sea-salt aerosol is responsible for the bulk of the aerosol optical extinction, with MBL sulfate AOD ranging from $0.01-0.03$ and sea-salt AOD ranging from $0.01-0.10$ (0.05 - 0.10 under moderate winds).

\section{IMPACT/APPLICATIONS}

Aerosols scatter and absorb EM radiation and are a primary source of extinction in the visible and IR portions of the EM spectrum. To calculate aerosol extinction as a function of wavelength requires 
knowledge of the aerosol size distribution along the optical path. Hence aerosols are important to: (i) DoD systems which use visible or IR wavelengths, such as EO (electro-optical) systems for surveillance, guidance and control, (ii) remote sensing in the visible and IR where aerosol corrections are often important (example: sea-surface temperature), and (iii) radiative transfer calculations required in global and climate models.

Long term impact. While detailed microphysical aerosol models which can predict the aerosol size distribution are in their infancy, rapid progress is being made in understanding the important physical and chemical aerosol processes and integrating these processes into a comprehensive aerosol/meteorological model. This work is making a substantial contribution toward the next generation of aerosol modeling.

Immediate impacts. We have developed an interface between a microphysical aerosol model and a meteorological model that will provide the met data necessary to run the aerosol model under realistic conditions. While this model is not an operational model since the aerosol data necessary to initialize it is not routinely available, it is a valuable diagnostic tool to interpret data from field experiments that will improve our understanding of aerosol processes and aerosol sensitivity to meteorological conditions.

\section{TRANSITIONS}

We have shown that the aerosol deposition velocity currently used in all models is fundamentally incorrect for a surface source of aerosols; such as, sea-salt aerosol, and have provided a deposition velocity formulation which can be used for sea-salt aerosol in future models. This new formulation (Hoppel et al., 2002, 2005) can/should be used in all aerosol models for those particles that have a local source at the earth's surface. This includes the more numerous, less sophisticated bulk aerosol models (which carry aerosol mass, but do not determine the size distribution).

\section{RELATED PROJECTS}

Much of the work reported here was done in conjunction with the RED (rough evaporation duct) experiment sponsored by ONR 322 and SPAWAR 155. We plan to use the data from the RED experiment together with our aerosol modeling effort to derive and improved sea-salt aerosol source function. (http://sunspot.spawar.navy.mil/2858/index.html)

Increased interest in aerosols generated by the climate change program, by remote sensing requirements, and by radiative transfer calculations in global models is driving the growing interest and research funding for aerosols. It would be impossible to list all these efforts here. However there is very little work being done developing detailed aerosol processes models in the Climate Change program. The primary difference is in the scale of interest. Local visibility and DoD applications require spatial resolution on the local and regional scale, while climate modeling requires global characterization. It is clear, however, that the small-scale processes drive the larger scale phenomena, and are necessary for any predictive model of climate change. For climate change prediction the national program recognizes a need for process-oriented studies (in addition to global aerosol data) for evaluating the effect of different policy scenarios. 


\section{REFERENCES}

Fitzgerald, J.W., W.A. Hoppel, and F. Gelbard: A One-Dimensional Sectional Model to Simulate Multicomponent Aerosol dynamics in the Marine Boundary Layer. I. Model Description. $J$. Geophys. Res. 103, 16085-16102, 1998.

Fitzgerald, J.W., J.J. Marti, W.A. Hoppel, G.M. Frick and F. Gelbard: A One-Dimensional Sectional Model to Simulate Multicomponent Aerosol dynamics in the Marine Boundary Layer. II. Model Application. J. Geophys. Res., 103, 16103-16117, 1998.

Caffrey, P.F., W.A. Hoppel, J.J. Shi: A one-dimensional sectional aerosol model integrated with mesoscale meterological data to study marine boundary layer aerosol dynamics, J. Geophys. Res., in press, 2006.

Hoppel, W. A., P.F. Caffrey, and G. M. Frick: Particle deposition on water: Surface source versus upwind source, J. Geophys. Res., 110, D10206, doi:10.1029/2004JD005148, 2005.

Hoppel, W. A., G. M. Frick, and J. W. Fitzgerald: Surface source function for sea-salt aerosol and aerosol dry deposition to the ocean surface, J. Geophys. Res., 107(D19), 4382, doi:10.1029/2001JD002014, 2002.

PUBLICATIONS (since 2003, ONR supported projects only)

Caffrey, P.F., W.A. Hoppel, J.J. Shi: A one-dimensional sectional aerosol model integrated with mesoscale meterological data to study marine boundary layer aerosol dynamics, J. Geophys. Res., in press, 2006.

Hoppel, W. A., P.F. Caffrey, and G. M. Frick: Particle deposition on water: Surface source versus upwind source, J. Geophys. Res., 110, D10206, doi:10.1029/2004JD005148, 2005.

Hoppel, W. A., P.F. Caffrey, and G. M. Frick: Addition of vertical velocity to a one-dimensional aerosol and trace gas model. Memorandum Report NRL/MR/7228-05-8852, NTIS ADA430126, Naval Research Laboratory, Washington DC, 2005.

Hoppel, W. A., G. M. Frick, and J. W. Fitzgerald: Surface source function for sea-salt aerosol and aerosol dry deposition to the ocean surface, J. Geophys. Res., 107(D19), 4382, doi:10.1029/2001JD002014, 2002. 

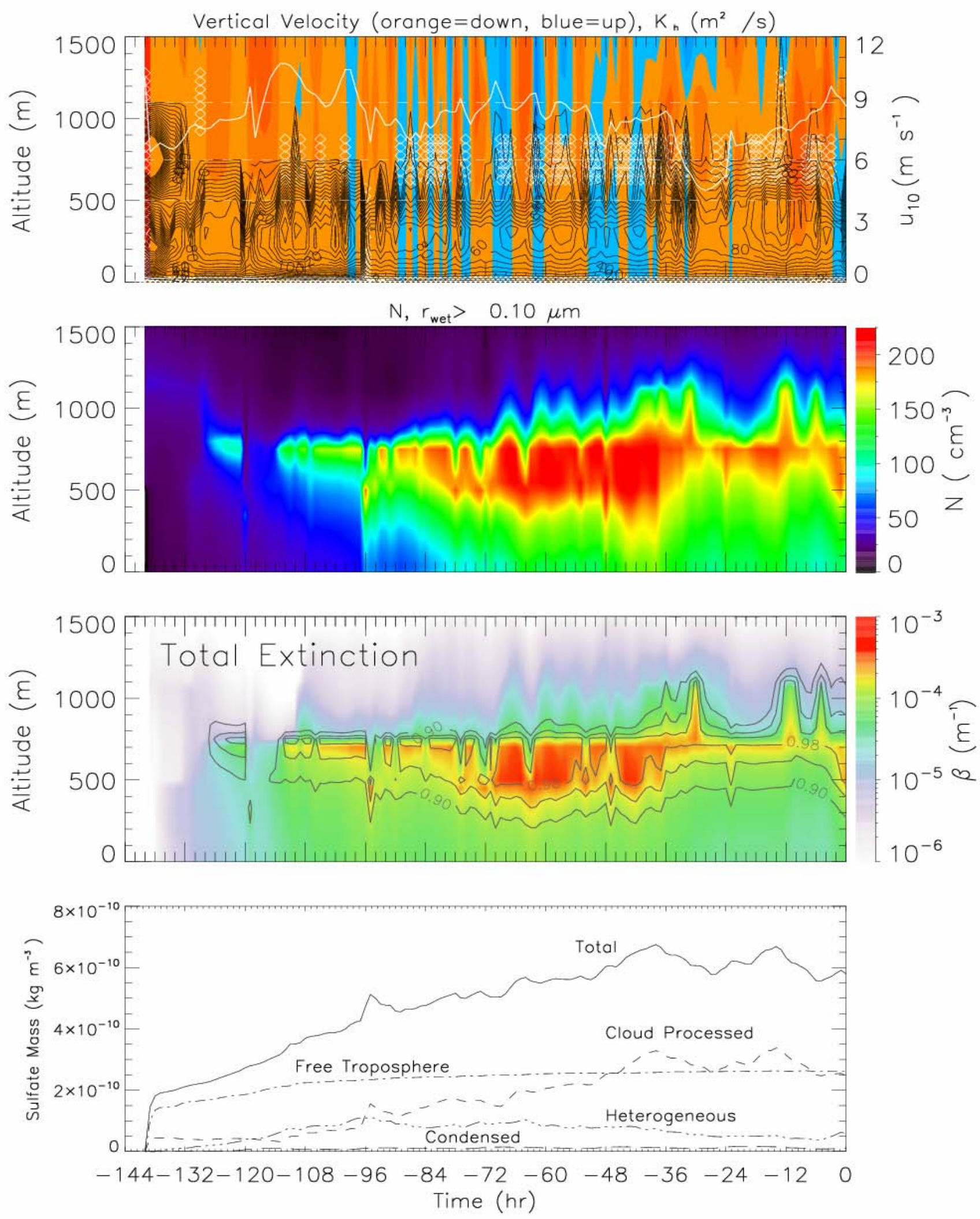

Figure 1. See text for explanation of panels. 